\title{
Geographic patterns of genetic variation in three genomes of North American diploid strawberries with special reference to Fragaria vesca subsp. bracteata
}

\begin{tabular}{|r|l|}
\hline Journal: & Botany \\
\hline Manuscript ID: & cjb-2015-0031.R2 \\
\hline Manuscript Type: & Article \\
\hline Complete List of Authors: & $\begin{array}{l}\text { Stanley, Lauren; University of Pittsburgh, Biological Sciences } \\
\text { Forrester, Nicole; University of Pittsburgh, Biological Sciences } \\
\text { Govindarajulu, Rajanikanth; University of Pittsburgh, Biological Sciences } \\
\text { Liston, Aaron; Oregon State University } \\
\text { Ashman, Tia-Lynn; University of Pittsburgh, Biological Sciences }\end{array}$ \\
\hline Keyword: & genetic structure, gynodioecy, hybridization, chloroplast, mitochondria \\
\hline & \multicolumn{2}{|l}{} \\
\hline
\end{tabular}

\section{SCHOLARONE ${ }^{m}$ \\ Manuscripts}



strawberries with special reference to Fragaria vesca subsp. bracteata

6 Lauren Stanley ${ }^{1}$, Nicole J. Forrester ${ }^{1}$, Rajanikanth Govindarajulu ${ }^{1}$, Aaron Liston ${ }^{2}$, and Tia-Lynn $7 \quad$ Ashman $^{1,3}$

8

$9{ }^{1}$ Department of Biological Sciences, University of Pittsburgh, Pittsburgh, Pennsylvania, 15260, 10 USA

$11{ }^{2}$ Department of Botany and Plant Pathology, Oregon State University, Corvallis, Oregon, 97331, 12 USA

13

$14{ }^{3}$ Author for correspondence (email: tia1@pitt.edu) fax: 412-624-4759; phone: 412-624-0984

15 Author emails:

16 Lauren Stanley (lauren.stanley@uconn.edu)

17 Nicole J. Forrester(njf26@pitt.edu)

18 Rajanikanth Govindarajulu (raj2010@pitt.edu)

19 Aaron Liston (listona@science.oregonstate.edu)

20 
21 Abstract: Geographic patterns of genetic variation in wild species reflect the interplay of

22 ecological and evolutionary processes. We assessed genetic variation in three genomes across

23 four North American diploid strawberry taxa, with special emphasis on the gynodioecious $F$.

24 vesca subsp. bracteata. Specifically, we sequenced one chloroplast (rpoC2) and two

25 mitochondrial (atp8 and atp8-orf225) genes along with several nuclear microsatellite markers. In

26 addition we assessed indicators of breeding system (pollen viability and female frequency) for

27 all taxa. The geographic perspective on the distribution of cytoplasmic and nuclear variation

28 revealed the genetic affiliation of the restricted taxa (F. v. subsp. californica and $F$. mexicana)

29 with the widespread $F$. v. subsp. bracteata and identified a hotspot of hybridization within

30 gynodioecious $F$. v. subsp. bracteata. Higher pollen viability of hermaphrodites was found in the

31 three hermaphroditic taxa relative to the gynodioecious one. Although theoretically predicted to

32 be associated, proportion females within F. v. subsp. bracteata populations, was not correlated

33 with population-level genetic variation, suggesting that the history of hybridization or population

34 size variation is more influential on the distribution of genetic variation than sex ratio in this

35 gynodioecious species. The documented patterns of genetic variation in this complex serve as an

36 important point of reference for future ecological and evolutionary research in diploid Fragaria.

37

38 Key words: chloroplast, hybridization, genetic structure, gynodioecy, mitochondria, pollen

39 viability

40 


\section{Introduction}

Patterns of phenotypic and genetic variation of wild species reflect their ecological and

44 evolutionary history. Important questions that have emerged are: How is variation partitioned 45 among and within populations for widespread species, and how differentiated and diverse are

46 rare species relative to widespread ones (Eckert et al. 2008; Gitzendanner and Soltis 2000;

47 Hamrick and Godt 1989)? Placing the answers to these questions in a geographic context can

48 contribute to a landscape-level perspective on how geographic and environmental features

49 influence gene flow, population structure and local adaptation in wild species (Manel et al.

50 2009).

51 Studying the landscape level patterns of genetic variation in all three plant genomes

52 (nucleus, chloroplast, and mitochondrion), in particular, can provide unique insight into the

53 distribution of genetic diversity within and among taxa. The cytoplasmic genomes (mitochondria

54 and chloroplast) are haploid and mostly maternally inherited in flowering plants (via ovules)

55 whereas the nuclear genome is biparentally inherited (via pollen and ovules). Thus, comparison

56 of geographic patterns of cytoplasmic genomes to nuclear ones can reveal the spatial pattern of

57 admixture (hybridization), as well as identify the prevailing direction of introgression via pollen

58 or seeds among highly differentiated populations or [sub]species (Matosiuk et al. 2014;

59 Seneviratne et al. 2012; Vekemans and Hardy 2004). Moreover, geographic patterns of nuclear

60 genome diversity can be assessed in light of species or population attributes that are expected to

61 affect diversity. For instance, aspects of the breeding system that enforce outcrossing, such as

62 gynodioecy (the coexistence of females and hermaphrodites), can lead to increased nuclear

63 genetic variation within populations and less differentiation among them than aspects of the 
64 breeding system that promote selfing, e.g., self-compatibility and hermaphroditism (Barrett

65 2003). Moreover, in gynodioecious species, the frequency of females can also affect how

66

67 genetic variation is partitioned within the population, i.e., population level of inbreeding.

Specifically, the higher the frequency of females, the lower the overall inbreeding level (Cuevas et al. 2006; Tarayre and Thompson 1997). Thus, comparisons among populations, or among closely related taxa, that differ in breeding system can provide insight into drivers behind the patterns of genetic diversity (Hamrick and Godt 1989).

Here we report the geographic patterns of genetic variation in all three genomes of North American diploid wild strawberries (Rosaceae). There are two widespread subspecies (Fragaria vesca subsp. bracteata [Heller] Staudt, and F. v. subsp. americana [Porter] Staudt), and two more restricted taxa (F.v. subsp. californica [Chamiso and Schlecht] Staudt, and F. mexicana Schlecht) (Fig. 1). All are interfertile (Bors and Sullivan 2005; R. Dalton et al. unpublished data). The subspecies $F$. v. subsp. bracteata, in particular, is of special interest because it is the maternal genome contributor to the octoploid progenitors (i.e., F. chiloensis and F. virginiana) of the cultivated strawberry (Fragaria $\times$ ananassa) (Govindarajulu et al. 2015; Njuguna et al. 2013; Tennessen et al. 2014). Fragaria $v$. subsp. bracteata is also notable because it is the only diploid Fragaria reported to have widespread sexual polymorphism (i.e., gynodioecy) (Ahmadi and Bringhurst 1989; Li et al. 2012). The male sterility reported in European F. vesca subsp. vesca (Irkaeva et al. 1993), in contrast, appears to be of limited occurrence (Ashman, T-L, unpublished data). This, plus the close affinity of $F$. v. subsp. bracteata to the octoploids, make it potentially influential in unraveling the evolution of male sterility and sex chromosomes in this clade (Tennessen et al. 2013). However, work-to-date has been based on only a few populations (Ahmadi and Bringhurst 1989; Li et al. 2012) and distinguishing the sexes has proven difficult 
87 (Li et al. 2012). Thus, broader surveys of female frequencies (i.e., sex ratio), and evaluation of 88 male fertility of hermaphrodites (i.e., pollen viability) are needed to fully verify sexual system 89 and to place this variation in a geographic context.

90 Phylogenetic analysis suggests there may be a subdivision in $F$. v. subsp. bracteata 91 between the Pacific Coast and Rocky Mountain populations (Njuguna et al. 2013). Analysis of 92 the chloroplast genome places some samples in a clade that includes the sexually dimorphic 93 octoploid species while other samples group with $F$. v. subsp. americana and European $F$. v. 94 subsp. vesca (Govindarajulu et al. 2015; Njuguna et al. 2013). However, more populations are 95 needed to fully characterize the geographic pattern of chloroplast diversity and to evaluate it in 96 light of speculation concerning a history of hybridization in F. v. subsp. bracteata (Staudt 1999). 97 Finally, Staudt (1999) notes that one of the diploid taxa, F. mexicana, is often considered synonymous with $F$. v. subsp. bracteata. However, the genetic affinity this taxon has relative to

99 all the subspecies has never been determined. Thus, documentation of the geographic patterns of 100 natural genetic variation for all the taxa in the North American diploid strawberry complex will 101 serve as an important point of reference for future ecological, evolutionary and functional 102 research in the strawberry genus (Liston et al. 2014; Shulaev et al. 2011). 104 diploid strawberries with special focus on $F$. v. subsp. bracteata. We verified the sexual system 105 differences of the taxa by characterizing female frequencies and pollen viability of 106 hermaphrodites. We determined whether sexual system affected nuclear genetic diversity across 107 all taxa. And finally, we used the genetic data to assess whether there has been a history of 108 hybridization within F. v. subsp. bracteata and to assess whether sexual system or sex ratio 109 affected population inbreeding level. 


\section{Materials and methods}

\section{Study System}

The four diploid $(2 \mathrm{n}=2 \times=14)$ Fragaria taxa have adjacent ranges in North

114 America (Fig. 1). Fragaria v. subsp. bracteata and F. v. subsp. americana have the

115 largest ranges, with $F$. v. subsp. bracteata extending from British Columbia south along

116 the Pacific Coast into California and east into the Rocky Mountains and F. v. subsp.

117 americana stretching from Canada's Northwest Territories west to British Columbia and

118 south along the Atlantic Coast to Virginia (Staudt 1999). Fragaria v. subsp. californica is

119 limited to coastal areas from southern Oregon to southern California with a disjunct

120 population in southern Baja California, Mexico, whereas $F$. mexicana is widespread but

121 disjunctly distributed at high elevations in Mexico south to the state of Chiapas (Staudt

122 1999). For the purposes of this study, we consider F. mexicana as distinct at the outset

123 and evaluate its affiliations with $F$.v. subsp. bracteata directly via genetic markers.

All four taxa are spring-blooming herbaceous perennials. They reproduce sexually by

125 seed (achenes) on fleshy "fruits" (swollen receptacle) or clonally by stolons. Three taxa (F.v.

126 subsp. americana, F. v. subsp. californica, and F. mexicana) are hermaphroditic and self-

127 compatible, whereas $F$. vesca subsp. bracteata is gynodioecious (Ahmadi and Bringhurst 1989;

128 Li et al. 2012). Flowers of female and hermaphrodite F. v. subsp. bracteata are morphologically

129 very similar, but anthers of pistillate flowers produce no viable pollen grains (Li et al. 2012). A

130 nuclear locus that affects sex expression with a dominant allele for male sterility has been

131 identified in material from a single population of $F$. v. subsp. bracteata from Oregon (Tennessen

132 et al. 2013). 
133 Sampling

134

135

136

137

138

139

140

141

142

143

144

145

146

147

148

149

150

151

152

153

154

To explore patterns of genetic variation across the subspecies and among nuclear and cytoplasmic genomes we used two sampling schemes: 1$)$ shallow sampling (11 populations at one plant/population) and 2) deep sampling (15 populations at four to 18 plants/population). For the 11 shallowly sampled populations dried leaves were obtained from our collections (1) or from the National Clonal Germplasm Repository (10) (NCGR:

http://www.ars.usda.gov/main/site_main.htm?modecode=53-58-15-00). For deep sampling, we sampled whole plants or fruits (one per maternal plant) along transects from nine populations of F. v. subsp. bracteata, two $F$. v. subsp. californica, three $F$. v. subsp. americana and one of $F$. mexicana. Plants or one seed per fruit were grown in the greenhouse at the University of Pittsburgh. For one deeply sampled population (ONT-GRL) leaves were obtained from fieldcollected seeds grown in the greenhouse by Brian Husband. Population names are represented as a combination of the state (province or country) of origin and a local place name (e.g., OR-MRD, 'Oregon' and 'Mary's Road'), GPS locations, collection sources and sampling intensity are summarized in Table A1.

\section{DNA extraction}

DNA was extracted from 100-150 mg of fresh leaf tissue or 20-30 mg of silica-dried leaf tissue per plant. We used a CTAB DNA protocol (Doyle and Doyle 1990), as modified in

Salamone et al. (2013). Nuclear genomic DNA was quantified for PCR using a Spectromax 190 spectrophotometer (Molecular Devices, Sunnyvale, California, USA) and subsequently diluted with deionized sterile water $(0.1-0.3 \mathrm{ng} / \mathrm{mL})$ as needed.

\section{Amplification and sequencing of chloroplast and mitochondrial genes.}


We amplified ca. $700 \mathrm{bp}$ of the rpoC2 chloroplast gene region using published primers

156

157

158

159

160

161

162

163

164

165

166

167

168

169

170

171

172

173

174

175

176

177

(Table A2). The PCR reaction included 1X standard reaction buffer (New England Biolabs), 100 $\mu \mathrm{M}$ of each dNTP, $0.5 \mu \mathrm{M}$ of each forward and reverse primers, 1.5 units of Standard Taq polymerase (New England Biolabs) and $1 \mu 1$ of genomic DNA in a $20 \mu 1$ reaction. The amplification conditions were 2.5 minutes at $95^{\circ} \mathrm{C}$, followed by 35 cycles of $95^{\circ} \mathrm{C}$ for 30 seconds, $52^{\circ} \mathrm{C}$ for 30 seconds, and $72^{\circ} \mathrm{C}$ for 60 seconds, and a final extension at $72^{\circ} \mathrm{C}$ for eight minutes.

To assess mitotype diversity, we sequenced $425-746$ bp portions of ten mitochondrial genes (atp4, atp6, atp8, atp9, cob, cox3, nad6, nad9, rps1) and a novel ORF (atp8-orf225) using published primers or those developed herein (i.e., for atp8, rps1 and atp8-orf225) (Table A2). PCR amplification used the conditions described above for the chloroplast gene with annealing temperatures between $48-54^{\circ} \mathrm{C}$ (Table A2).

The ten mitochondrial genes were screened in one individual from 10 populations to first test for polymorphism. Of these only two showed any polymorphism (atp 8 and $r p s 1$ ) and we selected the one with a greater number of mitotypes for further study (351 bp of atp 8 ). The atp 8 orf225 is a novel 294 bp open reading frame (ORF) with a putative role in cytoplasmic male sterility and a phylogenetic signal inconsistent with the rest of the mitochondrial genome but consistent with the chloroplast genome (Govindarajulu et al. 2015; Tennessen et al. 2013). We amplified $425 \mathrm{bp}$ of atp8-orf225 (including flanking sequence to avoid co-amplification of the full length atp 8 gene) using primers in Table A2.

The amplified PCR products of both chloroplast and mitochondrial genes were purified using Exo-SAP (Affymetrix/USB, Cleveland, OH) and sequenced on the ABI 3730XL DNA Analyzer (Applied Biosystems, Sunnyvale, CA). Sequences were aligned using CodonCode Aligner (CodonCode Corporation, Centerville, MA) and edited using Bioedit (Hall 1999). 
178

179

180

181

182

183

184

185

186

187

188

189

190

191

192

193

194

195

196

197

198

199

200

\section{Nuclear genotyping}

For the 15 deeply sampled populations (Table A1) we also genotyped four to 18 plants (174 plants in total) at five nuclear microsatellite markers: CX661603, CX661264, UDF002, ARSFL 7, and Fvil1 following Li et al. (2012). Each marker was amplified using the Poor Man's protocol (Govindarajulu et al. 2013; Schuelke 2000). The PCR products for all five primers were either run separately or multiplexed using $1.5 \mu$ aliquots from each reaction with $0.2 \mu \mathrm{l}$ LIZ500 standard and 10.5 $\mu \mathrm{l} \mathrm{Hi-Di} \mathrm{formamide} \mathrm{(Applied} \mathrm{Biosystems,} \mathrm{Carlsbad,} \mathrm{CA).}$ Fragment analysis was performed using the ABI 3730XL DNA Analyzer. Product sizes were visualized and genotyped using the program GeneMapper ver. 3.0 (Applied Biosystems).

\section{Genetic analyses}

Sequences derived from all samples of $r p o C 2$ were aligned to visualize SNPs at two informative positions 2934 bp ( $\mathrm{G}$ and C) and 3045bp (T and C). Previously SNPs at the second site (only) in this region were used to differentiate Pacific Coast $F$. v. subsp. bracteata from Rocky Mountain F. v. subsp. bracteata and F. v. subsp. americana (Njuguna et al. 2013). Here we present both SNP positions to facilitate comparison with past data sets, and refer to the G/T and $\mathrm{C} / \mathrm{C}$ as chlorotype 1 and 2, respectively. The nucleotide polymorphisms observed in atp 8 and atp8-orf 225 were scored for each sequence and both separate and concatenated mitotype designations were made for all samples. We calculated the number of mitotypes, number of segregating sites and mitotype diversity within and across the deeply sampled populations using DNaSP ver. 5.10.1 (Rozas et al. 2010). Additionally, we tested for evidence of recombination between atp 8 and atp8-orf 225 in all individuals from the deeply sampled populations using the four-gamete test (Hudson and Kaplan 1985) as implemented in DNaSP. Using all distinct haplotypes found in the study (regardless of source population), we created individual minimum 
201 spanning trees for atp8, atp8-orf225, concatenated atp8-orf $225+$ atp 8 and rpoC2 in

202 Arlequin ver. 3.5.1.3 (Excoffier and Lischer 2010). We did not concatenate chloroplast

203 and mitochondrial genes because there is evidence that they are unlinked (Govindarajulu

204 et al. 2015). To visualize minimum spanning networks, we constructed haplotype

205 networks in HapStar (Teacher and Griffiths 2011).

206 To characterize nuclear genetic diversity in the deeply sampled populations, we

207 calculated the number of polymorphic loci in Microsatellite Toolkit ver. 3.1.1 (Park 2001).

208 Allelic richness and Weir and Cockerham's global $F_{S T}$ were estimated in FSTAT ver. 2.9.3.2

209 (Goudet 2002). $F_{S T}$ was calculated for all taxa together and then for $F$. v. subsp. bracteata alone.

210 Wright's inbreeding coefficient $\left(F_{\text {IS }}\right)$ was only calculated for populations with more than one

211 polymorphic locus, and only plants with genotypic data for at least three of the five SSR loci

212 were included in these analyses $(n=166)$. Allelic richness was used as an indicator of population

213 admixture and size because it can detect bottlenecks even before substantial loss of

214 heterozygosity occurs (Comps et al. 2001; Luikart et al. 1998).

To investigate admixture between the subspecies, we performed a Bayesian

216 model-based clustering analysis in STRUCTURE ver. 2.3.3 (Pritchard et al. 2000) on the

21715 deeply sampled populations. Individuals $(\mathrm{n}=166)$ were assigned probabilistically to $K$

218 inferred genetic clusters, each characterized by a set of allele frequencies at Hardy-

219 Weinberg equilibrium and in linkage equilibrium. We ran the program with the

220 admixture model and independent allele frequencies for a range of $K$ values from 1 to 15 .

221 We used 10,000 burn-ins and Monte Carlo Markov Chain replicates for each run, with 10

222 replicate runs conducted for each $K$ value. We used Structure Harvester (Earl and

223 vonHoldt 2012) to calculate a $\Delta K$ value that indicates the optimal number of genetic 
224 clusters based on methods from Evanno et al. (2005). The final matrix of nuclear membership for 225 each individual and population was visualized using DISTRUCT ver. 1.1 (Rosenberg 2007).

The geographic distribution of the chloroplast (rpoC2) and mitochondrial (atp8-orf225

227 and atp8) haplotypes was visualized in the program DIVA-GIS (Hijmans et al. 2007). Data from

228 the F. v. subsp. bracteata individuals from nine locations with known $F$. v. subsp. bracteata or $F$.

$229 v$. subsp. americana-type chloroplast SNPs (Njuguna et al. 2013) were also included on the map

230 for comparative purposes.

\section{Sexual system}

For each deeply sampled population, the proportion of females was estimated from either surveys (sexual identity of flowering plants every $2 \mathrm{~m}$ [to avoid sampling the same clone] along two to three 20m transects in the field; as in Ashman 1999) or from sexual identity of greenhouse grown plants (or one seed per fruit) that were collected similarly along transects in the field.

236 Sample size per population (Table 1) depended on plant abundance and ranged. Hermaphrodite 237 plants had plump yellow anthers that visibly shed pollen, whereas individuals whose anthers 238 were lighter yellow or pale and that never dehisced were categorized as female (following Li et 239 al. 2012). We assessed pollen viability of hermaphrodite plants in the deeply sampled populations by collecting dehiscing anthers from two freshly opened flowers per plant grown

242 was scored visually under a light microscope for $>100$ pollen per flower (Kearns and Inouye 243 1993). The proportion of viable grains was calculated for each flower, averaged per plant, and 244 the mean calculated for each population from plant means. Anthers from individuals classified as 245 females were also assessed using this method to confirm qualitative assessment of sexual identity 246 (i.e., no pollen produced). Populations with no females were considered hermaphroditic, while 
247 populations with female individuals were considered gynodioecious.

\section{$248 \quad$ Sexual system analyses}

To assess whether sexual system affected nuclear genetic diversity (population-

250 level inbreeding, allelic richness), we conducted a $t$-test comparing the mean nuclear

251 genetic diversity metrics of all populations from hermaphroditic taxa $(F . v$. subsp.

252 americana, $F$. v. subsp. californica, and $F$. mexicana) to that of populations from the

253 gynodioecious subspecies ( $F$. v. subsp. bracteata). We also evaluated the relationship

254 between female frequency, pollen viability and nuclear genetic diversity across all $F$. $v$.

255 subsp. bracteata populations using Pearson correlations. Pearson correlations are viewed

256 as an adequate choice even for zero inflated data (Huson 2007). All analyses were

257 implemented in R (R Core Development Team 2012).

258 Nuclear microsatellite data were deposited at Dryad (http://dx.doi.

$259 \operatorname{org} / \mathrm{XXX}$ ), while chloroplast and mitochondrial gene sequences were deposited in Genbank atp8:

260 KM107197 - KM107311; atp8-orf225: KM107312 - KM107426; rpoC2: KM107427 -

261 KM107563).

262

263 Results

264 Diversity in chloroplast and mitochondrial genes

265 Sequencing of chloroplast gene rpoC2 in 25 wild populations of diploid Fragaria

266 in North America (Fig. 2a) confirmed the existence of two distinct types (Njuguna et al.

267 2013). All deeply sampled populations of $F$. v. subsp. americana were chlorotype 1, but

268 those of F. v. subsp. bracteata were either monomorphic for chlorotype 1 (four

269 populations) or 2 (three populations), or were polymorphic (three populations: \% type 1: 
270 OR-ES: 60\%; OR-FB: 10\%; ID-SFR: 78\%). The deeply sampled F. v. subsp. californica

271 populations were monomorphic for chlorotype 2, whereas $F$. mexicana was monomorphic for

272 chlorotype 1, in agreement with the single shallowly sampled population of this subspecies (MX-

273 PE). Thus, F. v. subsp. californica was indistinguishable from Pacific Coast F. v. subsp.

274 bracteata, while $F$. mexicana was indistinguishable from Rocky Mountain $F$. v. subsp. bracteata 275 and F. v. subsp. americana at the chloroplast gene rpoC2.

Both mitochondrial genes amplified in all but one population. A total of eight SNPs were

277 found, three in atp 8 and five in atp8-orf 225 . We did not detect any recombination events

278 between atp8 and atp8-orf225 based on our four-gamete test (Hudson and Kaplan 1985). Thus

279 there were eight unique concatenated atp 8 -orf $225+$ atp 8 sequences, referred to as mitotypes A-H

280 (Table 1, Fig. 2b; Table A3). Minimum spanning networks generated from concatenated atp8-

281 orf $225+$ atp 8 sequence characterized mitotype $\mathrm{H}$ as the most genetically distant from mitotype A.

282 Most $F$. v. subsp bracteata, both $F$. v. subsp. californica, and $F$. mexicana populations contained

283 mitotype B or C, and almost all of them (11/12) had the same SNP combination in atp8 (See

284 Table A3). The exception was population NM-LNF, which was fixed for a novel mitotype (F). In

285 contrast, the F. v. subsp. americana populations (NH-FP and ONT-GRL) had mitotype H, or

286 were missing concatenated mitotype information (IA-SSP) because the atp 8 -orf 225 would not

287 amplify [although atp8 would]. Population ONT-GRL also had two individuals with mitotype D.

288 Deep sampling revealed polymorphism within several populations of $F$. $v$ subsp. bracteata: three

289 were dimorphic (OR-MRD C/B: 90/10\%; ID-SFR E/C:70/30\% and CO-SCR C/G:70/30\%) and

290 one was trimorphic (OR-ES- G/C/E: 50/40/10\%). Mitotype diversity in these populations ranged

291 from 0.20-0.64 (Table 1). None of the deeply sampled F. v. subsp. californica, F. mexicana, nor

292 two of the three F. v. subsp. americana populations showed mitotypic polymorphism (Table 1). 
293 The single population of $F$. v. subsp. americana with polymorphism (ONT-GRL) was

294 unique among the polymorphic populations in that the two individuals with minority

295 mitotypes also had divergent nuclear affiliations (see below). It is also noteworthy that

296 with the exception of the two individuals with mitotype D in ONT-GRL, the rarer

297 mitotypes (E, F, and G) generally occur in the center of the network, showing sequences

298 intermediate between the more common B/C mitotypes and the $\mathrm{H}$ mitotype.

299

Networks based on atp 8 and atp8-orf 225 sequences separately revealed four

300

301

302

303

304

305

306

307

308

309

310

311

312 chlorotypes within F. v. subsp. bracteata (Fig. 3). Populations located west of the

313 Rockies were dominated by chlorotype 2 while those to the east were dominated by

314 chlorotype 1, thus following the distributional ranges of the widespread subspecies $(F$. $v$.

315 subsp. bracteata and $F$. v. subsp. americana). A hybrid zone extending from the Oregon 
316 Cascades to western Idaho is suggested by the three $F$. v. subsp. bracteata populations (OR-ES, 317 OR-FB, and ID-SFR) with mixed chlorotypes. chlorotypes, a longitudinal pattern was seen: The westernmost populations showed mitotypes B and/or C (all F. v. subsp. californica, F. mexicana and many F. v. subsp. bracteata), the easternmost populations (all $F . v$. subsp. americana) had mitotype H, whereas, the more central populations of $F$. v. subsp. bracteata showed admixture plus the occurrence of novel mitotypes

323 (E, F, and G). Two of the populations (OR-ES, ID-SFR) that were polymorphic in the mitochondrial genome also showed polymorphism in the chloroplast. These populations are between the Oregon Cascade and the Rocky Mountains in Idaho, and show the highest degree of cytoplasmic admixture (between them, three of the eight observed mitotypes and both of the

327 chlorotypes are represented). Separate from these geographic patterns, a novel mitotype (D) was 328 found in two individuals of ONT-GRL amongst other individuals with the majority mitotype $(\mathrm{H})$ 329 for F. v. subsp. americana (Figs. 2,3).

\section{Nuclear genetic variation shows differentiation and distinct population structure}

Analysis of microsatellite variation in the 15 deeply sampled populations revealed one to

332 five polymorphic loci per population and 1.1 to 2.6 alleles per locus (Table 1). There was

333 significant genetic differentiation among all North American diploid strawberry populations $\left(F_{\text {ST }}\right.$ $334=0.588)$ and among the nine $F$. v. subsp. bracteata populations $\left(F_{\mathrm{ST}}=0.476\right)$. Inbreeding ranged 33510 -fold $\left(F_{\text {IS }}=0.065\right.$ to 0.760 ; Table 1$)$ with significant inbreeding in six populations $(4$ of the 9 336 F. v. subsp. bracteata, one population of $F$. v. subsp. californica, and F. mexicana; Table 1). One 337 F. v. subsp. californica population (CA-SBNF) was only polymorphic at one locus, potentially 338 indicating high inbreeding as well. 
Structure analysis indicated the presence of two distinct genetic groups $(\Delta K=2$;

340

341

342

343

344

345

346

347

348

349

350

351

352

$-\ln L=-1971.12$; Fig. 4). The three populations of $F$. v. subsp. americana showed a high

proportion of nuclear membership to cluster $1(92 \pm 1 \%)$, whereas eight of the nine

populations of $F$. $v$. subsp. bracteata showed a high proportion of nuclear membership to cluster $2(97 \pm 2 \%)$. The only population to deviate from this pattern was NM-LNF, which showed high membership to cluster $1(97 \%)$. The southern $F$. v. subsp. californica and $F$. mexicana both showed affinity with cluster $2(99 \pm 0.05 \%)$. Overall, the geographic pattern of nuclear genetic variation followed the same east-west distribution seen in the chloroplast, which is consistent with the known ranges of $F$. v. subsp. americana and F. v. subsp. bracteata. There was little nuclear admixture observed within populations (less than $5 \%$ ) despite the admixture seen in the cytogenomes of three $F . v$. subsp. bracteata populations (OR-ES, OR-FB, and ID-SFR). Plants within these three populations all had nuclear affiliations to cluster 2 but a percentage of individuals within each had chlorotype 1 (OR-ES: 60\%, OR-FB: 10\%, ID-SFR: 78\%). We also detected two populations for which all sampled individuals demonstrated a mismatch between the nuclear and chloroplast affiliations: CO-SCR and MX-LV are strongly affiliated with cluster 2 (F. v. subsp. bracteata nuclear genome) but are both monomorphic for chlorotype 1 (F.v. subsp. americana type). The northern populations are located along the Rocky Mountains where hybridization is likely to occur. The other evidence of admixture comes from ONT-GRL, a population well within $F$. v. subsp. americana range, but hosting a minority of individuals $(2 / 10)$ that cluster with the $F$. v. subsp. bracteata (Fig. 4). These individuals are also novel in mitotype and could reflect recent migrants (potentially human introduced) or early generation hybrids. 


\section{Sex expression and correlates with population genetic diversity}

Consistent with current understanding of sexual systems in the North American diploid strawberries, females were only found in $F$. $v$. subsp. bracteata populations where they ranged in frequency from 0 - 46\% (Table 1). Moreover, hermaphrodites of $F$. v. subsp. bracteata had significantly lower mean proportion pollen viability than those of the hermaphroditic taxa $(F . v$. subsp. americana, $F$. v. subsp. californica and $F$. mexicana; Table 1) (mean \pm s.e.: $0.77 \pm 0.02$ vs. $\left.0.91 \pm 0.02, t_{13}=-4.70, p=0.001\right)$. While the inbreeding coefficient was not significantly different $\left(F\right.$. v. subsp. bracteata: $0.30 \pm 0.07 v s$. hermaphroditic taxa: $0.49 \pm 0.13, t_{13}=-1.32, p=$ 0.21 ), nuclear allelic richness was higher in populations of gynodioecious $F$. v. subsp. bracteata than those of the hermaphroditic taxa (F. v. subsp. americana, F. v. subsp. californica and $F$. mexicana) $\left(F\right.$. v. subsp. bracteata: $2.04 \pm 0.12 v s$. hermaphroditic taxa: $1.60 \pm 0.13, t_{13}=2.43, p$ $=0.03$; Table 1). Among the 9 populations of gynodioecious $F . v$. subsp. bracteata, however, we did not detect a significant correlation of female frequency with allelic richness, inbreeding nor mean pollen viability (all $p>0.10$ ). Although we note that some sample sizes are small.

\section{Discussion}

\section{Geographic patterns of genetic variation in North American diploid strawberries}

Geographic analysis of the three genomes of North American diploid Fragaria confirmed the known distributions of the widespread subspecies and gave insight into genetic affiliations of the more restricted taxa. Specifically, the structure analysis of nuclear markers aligned $F$. v. subsp. californica and $F$. mexicana with $F$. v. subsp. bracteata. Thus, these genetic results confirm Staudt's (1999) lumping of $F$. mexicana with $F$. v. subsp. bracteata based on phenotypic data. These two rarer taxa also reflect the chlorotype division observed in the wide spread $F . v$. 
384 subsp. bracteata with $F$. v. subsp. californica possessing the Pacific Coast chlorotype and $F$.

385 mexicana the Rocky Mountain chlorotype.

The mitochondria showed similar broad scale patterns to the chloroplast (especially with

387 respect to $F$. v. subsp. californica and $F$. mexicana), but revealed the potential for finer scale

388 diversity in the widespread species as well. Many populations were polymorphic and some

389 showed entirely novel mitotypes. For instance, within F. v. subsp. americana a novel mitotype

390 was found in the Guelph, Ontario population along with two individuals that were potentially

391 recent immigrants (i.e., were in the minority but belonged to the $F$. v. subsp. bracteata nuclear

392 cluster). Unfortunately, human introduction cannot be ruled out, considering the proximity to

393 University of Guelph, where diverse Fragaria species have been grown in the past (Bors and

394 Sullivan 2005). Whether this reflects the introduction of a novel mitotype in a $F$. v. subsp.

395 bracteata migrant, or if it is the result of undetected intragenomic recombination facilitated by

396 heteroplasmy (McCauley 2013) in association with hybridization (Kmiec et al. 2006) is

397 unknown. Additionally, in another F. v. subsp. americana population (IA-SSP) the primers for

398 atp8-orf225 did not amplify a product. This could reflect the loss of this gene from the

399 mitochondria in this population (as in Kmiec et al. 2006) or simply a mutation in the primer site.

400 Nonetheless, these data suggest that these mitochondrial genes are valuable for tracking fine-

401 scale geographic patterns. In fact, if atp8-orf225 (Govindarajulu et al. 2015), is confirmed to

402 have had a functional role in male sterility, then these patterns could reflect past cyto-nuclear

403 evolutionary dynamics (e.g., Städler and Delph 2002) in a species that at present is

404 phenotypically hermaphroditic.

405 Geographic patterns of genetic variation reveal hybridization in $F$. v. subsp. bracteata 
Our landscape-level analysis also identifies a zone of cytoplasmic introgression between

407 the Cascades and Northern Rocky Mountains where the ranges of $F$. v. subsp. bracteata and $F$. v. 408 subsp. americana contact. This discovery of admixed populations west of the Rocky Mountains 409 is consistent with Staudt's (1999) observations of hybrids between $F$. v. subsp. americana and $F$. $410 v$. subsp. bracteata in Yellowstone National Park and southwest of the Rocky Mountains. These 411 data plus Staudt's (1999) reports of hybrids between F. v. subsp. bracteata and F. v. subsp.

412 californica in Curry county in southern Oregon and Humboldt and Del Norte counties in 413 northern California define a hotspot of past admixture between these subspecies in Northern 414 California/Oregon/Idaho. This region is also an active area of hybridization in the octoploid 415 strawberries (Salomone et al. 2013) suggesting that both diploids and octoploids may have 416 responded in parallel to past climate change. In contrast with the octoploid hybrid populations, 417 however, F. v. subsp. bracteata populations showed few admixed individuals, consistent with the 418 high degree of population structure observed in the nuclear genome across this large area. Rocky 419 Mountain F. v. subsp. bracteata display a strong signal of introgression of the $F$. v. subsp. 420 americana chloroplast into $F$. $v$. subsp. bracteata nuclear background, suggesting long distance 421 seed dispersal followed by pollen swamping (Beatty et al. 2010), or extensive backcrossing after 422 a past hybridization event, as in Vasconcellea (Van Droogenbroeck et al. 2006) and Eucalyptus 423 (McKinnon et al. 1999). Alternatively, it could reflect chloroplast capture, possibly facilitated by 424 gynodioecy in this subspecies. Specifically, Tsitrone and colleagues (2003) show theoretically 425 that a combination of female seed advantage and partial selfing can lead to rapid replacement of 426 chloroplasts in hybridizing lineages. In the context of Fragaria, Li et al. (2012) showed that both 427 of these predicted promoters of chloroplast capture exist within F. v. subsp. bracteata.

428 Moreover, Govindarajulu et al. (2015) has ruled out incomplete lineage sorting for the taxa in 
429 question, and there is high support that $F$. v. subsp. americana and $F$. v. subsp. bracteata are in 430 distinct clades, with $F$. mexicana and $F$. v. subsp. californica being in the same clade as $F$. v. 431 subsp. bracteata (Syring et al. ms. in prep.). Thus, we conclude that the pattern of chloroplast432 nuclear mismatches documented here reflect recent signatures of introgression where the taxa 433 come in contact.

It is interesting to note as well that two distant populations in Colorado and Mexico (COSCR, MX-LV) have the same cyto-nuclear incongruence ( $F . v$. subsp. americana chloroplast with $F$. v. subsp. bracteata nuclear genome) and one could speculate that it reflects range expansion of a single hybrid lineage, or strong ecological advantage of this combination over the alternative (F.v. subsp. bracteata chloroplast with $F$. v. subsp. americana nuclear genome). The adaptive value of sequence variation of cytoplasmic genomes, as well as the opportunity for ecological differentiation by nuclear-cytoplasmic interactions is only just now being appreciated

441 (reviewed in Bock et al. 2014). Specific adaptive effects of cytoplasmic genome variation have been observed with regard to drought and thermal tolerances (Ballard and Melvin 2010; Sambatti et al. 2008), which could also be important for diploid Fragaria along the continental divide.

444 The NM-LNF population is also interesting as it is a high elevation 'island' in the midst of desert 445 and thus could be a relic of past glaciation, or simply genetic drift. This population has a high 446 frequency of females, which could also be the result of founder events and restricted gene flow. 447 These types of forces have been found to be the primary determinants of sex ratio in other 448 gynodioecious species (e.g., Beta vulgaris; DeCauwer et al. 2012). More populations along this 449 southern range are needed to understand the patterns of genetic admixture and phylogeography 450 of diploid Fragaria in this region and to test these hypotheses explicitly. Artificial hybridization 451 and transplant experiments would also be particularly useful (e.g., Sambatti et al. 2008). 


\section{Sexual system variation and its effects on genetic diversity in F. v. subsp. bracteata}

Eight of the nine F. v. subsp. bracteata populations showed clear evidence of females confirming the existence of gynodioecy in this subspecies over a much wider geographic range than previously studied (Ahmadi and Bringhust 1989). Sex ratio varied dramatically (from 0$46 \%$ females) as is common in gynodioecious species (e.g., Medrano et al. 2005; Nilsson and

457 Ågren 2006), but there was no relation between female frequency and population-level inbreeding. Although such a relation has been found in three species (Kallstroemia grandiflora (Cuevas et al. 2006), Daphne laureola (Medrano et al 2005), and Schizopepon bryoniaefolius (Akimoto et al. 1999)), our work joins the findings of Tarayre and Thomspson (1997) who failed to find a negative relation between female frequency and population-level inbreeding in Thymus vulgaris. We hypothesize that factors such as gene flow or drift, as the result of past hybridization or population bottlenecks, have stronger fingerprints on genetic diversity than

464 gynodioecy, or that biparental inbreeding occurs in females neutralizing their expected effect on 465 population inbreeding level. The latter explanation may hold for Thymus vulgaris where there

467 Thompson 1997). In contrast, however, in F. v. subsp. bracteata, Li et al. (2012) found no 468 biparental inbreeding by females but significant inbreeding by hermaphrodites. So if the results 469 in one population (OR-MRD) studied by Li et al. (2012) are representative then the explanation 470 may instead lie with the patterns of gene flow and drift. The present work provides evidence of

471 the existence of the former: we found introgression in about half of the $F$. $v$. subsp. bracteata

472 populations. A final alternative is that our sample size of populations or individuals was not

473 adequate to reveal a relationship that exists. Deeper and broader sampling and knowledge of

474 population size would ultimately be needed to distinguish among these possibilities. 
Interestingly, the lower average pollen viability for hermaphrodites from $F$. v.

476

477

478

479

480

481

482

483

484

485

486

487 Dufay et al. 2008).

488

489

490

491

492

493

494

495

496

\section{Acknowledgements}

subsp. bracteata populations compared to those from hermaphroditic taxa could also

reflect hybridization because frequently hybridizing species can have lower pollen

viabilities than rarely hybridizing ones (e.g., Cirsium, Bureš et al. 2010). Specifically, cyto-nuclear mismatches can cause pollen dysfunction, as has been seen in Helianthus and Oenothera (Levin 2003; Stubbe and Steiner 1999), and are thought to result from breakdown of coadapted interactions between organelle and nuclear genomes (reviewed in Burton et al. 2013). Alternatively, pollen inviability may be directly related to the influence of the chimeric open reading frame atp8-orf225, which is known to be expressed (Liston A. and R.C. Cronn, unpublished data), and is a candidate for a cytoplasmic male sterility gene (Govindarajulu et al. 2015). If the latter is the case, then populations must vary in the degree that expression is regulated by other factors (e.g.,

\section{Conclusions and future work}

This landscape-level study of genetic variation in the four diploid strawberry taxa adds important genetic insight to the biogeographic history of North American strawberries. It confirms the differences in sexual system among the taxa and starts to untangle the effects on genetic diversity. Future work in $F$. v. subsp. bracteata should be aimed at expanding the sampling in the southern portion of its range and determining the bioclimatic triggers of the geographic pattern of cyto-nuclear association observed in its nothern hybrid zone. 
The authors thank A. Grant, G. Arceo-Gomez, G. Meindl, S. Falk, M. Koski, M. Parks,

498 T. Rabogliatti, K. Schuller for greenhouse, field or laboratory assistance, the Ashman lab for

499 discussion, B. Husband for leaf tissue from plants from ONT-GRL, the editor and two

500 anonymous reviewers for comments that improved the manuscript. This work was supported by

501 the University of Pittsburgh, the National Science Foundation (DEB 1020523 and RET/REU

502 supplements to TLA and DEB 1020271 to AL), and HHMI Fellowship to LS.

503

504 References

505 Ahmadi, H., and Bringhurst, R.S. 1989. Genetics of sex expression in Fragaria species. Am. J.

506 Bot. 78:504-514.

507 Akimoto, J., Fukuhara, T., and Kikuzawa, K. 1999. Sex ratios and genetic variation in a 508 functionally androdioecious species, Schizopepon bryoniaefolius (Cucurbitaceae). Am. J. Bot. 86: $880-886$.

510

511

512

513

514

515

516

517

518

Ashman, T-L. 1999. Determinants of sex allocation in a gynodioecious wild strawberry: implications for the evolution of dioecy and sexual dimorphism. J. Evol. Biol. 12:648661.

Ballard, J., and Melvin, R. 2010. Linking the mitochondrial genotype to the organismal phenotype. Mol. Ecol. 19:1523-1539.

Barrett, S.C.H. 2003. Mating strategies in flowering plants: the outcrossing-selfing paradigm and beyond. Phil. Trans. R. Soc. Lond. 358:991-1004.

Beatty, G.E., Philipp, M., and Provan, J. 2010. Unidirectional hybridization at a species' range boundary: implications for habitat. tracking. Div. Distr. 16:1-9. 
519 Bock, D., Andrew, R., and Rieseberg, L. 2014 On the adaptive value of cytoplasmic genomes in 520 plants. Mol. Ecol. 23:4899-4911.

521 Bors, R., and Sullivan, J. 2005. Interspecific hybridization of Fragaria vesca subspecies with $F$. nilgerrensis, F. nubicola, F. pentaphylla, and F. viridis. J. Amer. Soc. Hort. Sci. 130:418-

Bureš, P., Šmarda, P., Rotreklová, O., Oberreiter, M. Burešová, M., Konečný, J., Knoll, A., 525 Fajmon, K., and Šmerda, J. 2010. Pollen viability and natural hybridization of Central

Burton, R.S., Pereira, R.J., and Baretto, F.S.. 2013, Cytonuclear genomic interactions and hybrid breakdown. Annu. Rev. Ecol. Evol. Syst. 44:281-302

529 530 European species of Cirsium. Preslia 82:391-422.

Comps, B., Gömöry, D., Letouzey, J., Thiébaut, B., and Petit, R.J. 2001. Diverging trends between heterozygosity and allelic richness during postglacial colonization in the European Beech. Genetics. 157:389-397.

Cuevas, E., Arias, D.M., Dominguez, C.A., Castillo, R.A., and Molina-Freaner, F. 2006. The genetic structure of the gynodioecious Kallstroemia grandiflora (Zygophyllaceae): the role of male sterility and colonization history. Heredity 97: 269-274.

Dalton, R., Koski, M., and Ashman, T-L. 2013. Maternal sex effects and inbreeding depression under varied environmental conditions in gynodioecious Fragaria vesca subsp. bracteata Ann. Bot. 112:613-621.

DeCauwer, L., Dufay, M., Hornoy, B., Courseaux, A., and Arnaud, J-F. 2012. Gynodioecy in structured populations: understanding fine-scale sex ratio variation in Beta vulgaris ssp. maritime. Mol. Ecol. 21:834-850.

Doyle, J.J., and Doyle, J.L. 1990. Isolation of plant DNA from fresh tissue. Focus 12:13-15. 
542 Dufay, M., Vaudey, V., DeCauwer, I., Touzet, P., Cuguen, J., Arnaud, J. 2008. Variation in 543 pollen production and pollen viability in natural populations of gynodioecious Beta

544 545 546 547 548 549 550 551 vulgaris ssp. maritima: evidence for a cost of restoration of male function? J. Evol. Biol. 21: 202-212.

Earl, D.A., and vonHoldt, B.M. 2012. STRUCTURE HARVESTER: a website and program for visualizing STRUCTURE output and implementing the Evanno method. Cons. Gen. Res. 4:359-361.

Eckert, C.G., Samis, E., and Lougheed, S.C. 2008. Genetic variation across species’ geographical ranges: the central-marginal hypothesis and beyond. Mol. Ecol 17:11701188.

Evanno, G., Regnaut, S., and Goudet, J. 2005. Detecting the number of clusters of individuals using the software structure: a simulation study. Mol. Ecol. 14:2611-2620.

Excoffier, L., and Lischer, H.E.L. 2010, Arlequin suite ver 3.5: A new series of programs to perform population genetics analyses under Linux and Windows. Mol. Ecol. Res. 10:564567.

Gitzendanner. M.A. and Soltis, P.S. 2000. Patterns of genetic variation in rare and widespread plant congeners. Am. J. Bot. 87:783-792.

Goudet, J. 2002. FSTAT, a program to estimate and test gene diversities and fixation indices. version 2.9.3.2.

Govindarajulu, R., Liston, A., and Ashman, T-L. 2013. Sex-determining chromosomes and sexual dimorphism: insights from genetic mapping of sex expression in a natural hybrid Fragaria $\times$ ananassa subsp. cuneifolia. Heredity 110:430-438. 
564 Govindarajulu, R., Parks, M., Tennessen, J.A., Liston, A., and Ashman, T-L. 2015. Comparison

565 of nuclear, plastid and mitochondrial phylogenies and the origin of wild octoploid

566 strawberry species. Am. J. Bot. 102: 544-554.

567 Hall, T.A. 1999. BioEdit: A user-friendly biological sequence alignment editor and analysis

568 program for Windows 95/98/NT. Nucl. Acid. Symp. Series. 41:95-98.

569 Hamrick, J.L. and Godt, M.J.W. 1989. Allozyme diversity in plant species. In A. H. D. Brown, 570 M. T. Clegg, A. L. Kahler, and B. S. Weir [eds.], Plant population genetics, breeding, and genetic resources pp. 43-63. Sinauer, Sunderland, Massachusetts, USA.

572 Hijmans, R.J., Gavrilenko, T., Stephenson, S., Bamberg, J., Salas, A., and Spooner, D.M. 2007. Geographical and environmental range expansion through polyploidy in wild potatoes (Solanum section Petota). Global Ecol. Bio. 16:485-495.

575

Hudson, R.R., and Kaplan, N. 1985. Statistical properties of the number of recombination events in the history of a sample of DNA sequences. Genetics 111:147-165.

577 Huson, L.W. 2007. Performance of some correlation coefficients when applied to zero-clustered data. J of Mod Appl Stat Meth. 6:530-536.

579 Irkaeva, N.M., Lebedeva, L.V., and Shaziyatova, D.S. H. 1993. Genetics of male sterility in the 580 strawberry Fragaria vesca L. Soviet Genetics 29:1103-1107.

581 Kearns, C.A., and Inouye, D.W. 1993. Techniques for Pollination Biologists. Univ. Press of 582 Colorado, Boulder.

583 Kmiec, B., Woloszynska, M., and Janska, H. 2006. Heteroplasmy as a common state of 584 mitochondrial genetic information in plants and animals. Curr. Genet. 50:149-159. 585 Levin, D.A. 2003. The cytoplasmic factor in plant speciation. Syst. Bot. 28:5-11 
586 587

588 589

590

591

592

593 594 595 596 597 598 599 600 601 602 603 604 605 606 607 608

Li, J., Koski, M.H., and Ashman, T-L. 2012. Functional characterization of gynodioecy in Fragaria vesca ssp. bracteata (Rosaceae). Ann. Bot. 109:545-552.

Liston, A., Cronn, R.C., and Ashman, T-L. 2014. Fragaria: a genus with deep historical roots and ripe for evolutionary and ecological insights. Am. J. Bot. 101:1686-1699.

Luikart, G., Sherwin,W.B., Steele, B.M., and Allendorf, F.W. 1998. Usefulness of molecular markers for detecting population bottlenecks via monitoring genetic change. Mol. Ecol. 7:963-974.

Manel, S. Schwartz, M.K., Luikart, G. and Taberlet. P. 2003. Landscape genetics: combining landscape ecology and population genetics. Trends Ecol. Evo. 18:189-197.

Matosiuk, M., Borkowska, A., Świsłocka, M., Mirski, P., Borowski, Z., Krysiuk, K., Danilkin, A.A., Zvychaynaya, E.Y., Saveljev, A.P., and Ratkiewicz, M. 2014. Unexpected population genetic structure of European roe deer in Poland: an invasion of the mtDNA genome from Siberian roe deer. Mol. Ecol. 23:2559-2572.

McCauley, D. 2013. Paternal leakage, heteroplasmy, and the evolution of plant mitochondrial genomes. New Phytol. 200:966-977.

McKinnon, G., Steane, D., Potts, B., and Vaillancourt, R. 1999. Incongruence between chloroplast and species phylogenies in Eucalyptus subgenus Monocalyptus (Myrtaceae). Am. J. Bot. 86:1038-1046.

Medrano, M., Alonso, C., and Herrera, C.M. 2005. Mating system, sex ratio, and persistence of females in the gynodioecious shrub Daphne laureola L. (Thymelaeaceae). Heredity 94 : $37-43$.

Nilsson, E. and Ågren. J. 2006. Population size, female fecundity, and sex ratio variation in gynodioecious Plantago maritime. J. Evol. Biol. 19:825-833. 
609 Njuguna, W., Liston, A., Cronn, R.C., Ashman, T-L., and Bassil, N. 2013. Insights into

610 phylogeny, sex function and age of Fragaria based on whole chloroplast genome

611 sequencing. Mol. Phylo. Evol. 66:17-29.

612 Park, S. 2001 Trypanotolerance in West African cattle and the population genetic effects of 613 selection. PhD diss. University of Dublin, Ireland.

614 Pritchard, J., Stephens, M. and Donnelly, P. 2000. Inference of population structure using 615 multilocus genotype data. Genetics 155:945-959.

616 R Core Development Team 2012 R statistical software.

617 Rosenberg, N.A. 2007. Distruct: a program for the graphical display of population structure.

618

619 Rozas, J., Librado, P., Sánchez-DelBarrio, J.C., Messeguer, X. and Rozas, R. 2010. DNASSP

620 version 5.10.1.http://www.ub.edu/dnasp/.

621 Salamone, I., Govindarajulu, R., Falk, S., Parks, M., Liston, A., and Ashman, T-L. 2013

622 Bioclimatic, ecological, and phenotypic intermediacy and high genetic admixture in a

623 natural hybrid of octoploid strawberries. Am. J. Bot. 100:939-950.

624 Sambatti, J., Ortiz-Barrientos, D., Baack, E., and Rieseberg, L. 2008. Ecological selection 625 maintains cytonuclear incompatibilities in hybridizing sunflowers. Ecol. Let. 11:1082-

626 1091.

627 Schuelke, M. 2000. An economic method for the fluorescent labeling of PCR fragments. Nature 628 Biotech. 18:233-234.

629 Seneviratne, S., Toews, D.P.L., Brelsford, A. and Irwin, D.E. 2012. Concordance of genetic and 630 phenotypic characters across a sapsucker hybrid zone. J. Avian Biol. 43:119-130. 
631 Shulaev, V., Sargent, D.J., Crowhurst, R.N., Mockler, T.C., Folkerts, O., Delcher, A.L., Jaiswal,

632

633

634

635

636

637

638

639

640

641

642

643

644

645

646

647

648

649

650

651

652

653

P., Mockaitis, K., Liston, A., Mane, S.P., Burns, P., Davis, T.M., Slovin, J.P., Bassil, N., Hellens, R.P., Evans, C., Harkins, T., Kodira, C., Desany, B., Crasta, O.R., Jensen, R.V., Allan, A.C., Michael, T.P., Setubal, J.C., Celton, J-M., Rees, D.J.G., Williams, K.P., Holt, S.H., Ruiz Rojas, J.J., Chatterjee, M., Liu, B., Silva, H. Meisel, L., Adato, A. Filichkin, S., Troggio, M., Viola, R., Ashman, T-L., Wang, H., Dharmawardhana, P., Elser, J., Raja, R., Priest, H.D., Bryant Jr., D.W., Fox, S.E., Givan, S.A., Wilhelm, L.J., Naithani, S., Christoffels, A., Salama, D.Y., Carter, J., Lopez Girona, E., Zdepski, A., Wang, W., Kerstetter, R.A., Schwab, W., Korban, S.S., Davik, J., Monfort, A., DenoyesRothan, B., Arus, P., Mittler, R., Flinn, B., Aharoni, A., Bennetzen, J.L., Salzberg, S.L., Dickerman, A.W., Velasco, R., Borodovsky, M., Veilleux, R.E. and Folta, K.M. 2011. The genome of woodland strawberry, Fragaria vesca. Nature Gen. 43:109-116

Soltis, P.S., and Soltis, D.E. 2009. The role of hybridization in plant speciation. Ann. Rev. Plant Biol. 60:561-588.

Städler, T., and Delph, L. 2002. Ancient mitochondrial haplotypes and evidence for intragenic recombination in a gynodioecious plant. Proc. Nat. Acad. Sci. 99:11730-11735.

Staudt, G. 1999. Systematics and geographic distribution of the American strawberry species : taxonomic studies in the genus Fragaria (Rosaceae:Potentilleae). University of California Press, Berkeley.

Stubbe, W., and Steiner, E. 1999. Inactivation of pollen and other effects of genome-plastome incompatibility in Oenothera. Plant Syst. Evol. 217:259-77.

Tarayre, M., and Thompson, J.D. 1997. Population genetic structure of the gynodioecious Thymus vulgaris L. (Labiatae) in southern France. J. Evol. Biol. 10:157-174. 
654 Teacher, A.G.F., and Griffiths, D.J. 2011. HapStar: Automated haplotype network layout and 655 visualisation. Mol. Ecol. Res. 11:151-153.

656 Tennessen, J.A., Govindarajulu, R., Liston, A., and Ashman, T-L. 2013. Targeted sequence 657 capture provides insight into genome structure and genetics of male sterility in a 658 659 660 661 662 663 664 665 666 gynodioecious diploid strawberry, Fragaria vesca ssp. bracteata (Rosaceae). Genes Genomes Gen. 3:1341-1351.

Tennessen, J.A., Govindarajulu, R., Liston A., and Ashman, T-L. 2014. Evolutionary origins and dynamics of octoploid strawberry subgenomes revealed by dense targeted capture linkage maps. Genome Biol. Evol. 6:3295-3313

Toews, D.P.L., and Brelsford, A. 2012. The biogeography of mitochondrial and nuclear discordance in animals. Mol. Ecol. 21:3907-3930.

Tsitrone, A., Kirkpatrick, M., and Levin, D. 2003. A model for chloroplast capture. Evolution

667 Van Droogenbroeck, B., Kyndt, T.. Romeijn-Peeters, E., Van Thuyne, W., Goetghebeur, P., 668 669 670 Romero-Motochi, J., and Gheysen, G. 2006. Evidence of natural hybridization and introgression between Vasconcellea species (Caricaceae) from southern Ecuador revealed

671 Vekemans, X., and Hardy, O.J. 2004. New insights from fine-scale spatial genetic structure 672 analyses in plant populations. Mol. Ecol. 13:921-935. 


\section{Table 1}

Genetic and sexual system variation across 15 populations of North American diploid strawberry

\begin{tabular}{|c|c|c|c|c|c|c|c|c|c|c|c|}
\hline \multirow[b]{2}{*}{ Taxon } & \multirow{2}{*}{$\begin{array}{l}\text { Population } \\
\text { Code }\end{array}$} & \multirow[b]{2}{*}{$\mathrm{N}$} & \multirow{2}{*}{$\begin{array}{c}\text { Mitotype } \\
\text { atp8-orf } 225+ \\
\text { atp8 }\end{array}$} & \multirow{2}{*}{$\begin{array}{l}\text { Mitotype } \\
\text { Diversity }\end{array}$} & \multirow{2}{*}{$\begin{array}{c}\text { Chlorotype } \\
\text { rpoC2 }\end{array}$} & \multicolumn{2}{|c|}{ Nuclear Membership } & \multirow{2}{*}{$\begin{array}{l}\text { Allelic } \\
\text { Richness }\end{array}$} & \multirow[b]{2}{*}{$F_{\mathrm{IS}}$} & \multirow{2}{*}{$\begin{array}{c}\text { Proportion } \\
\text { Female }\end{array}$} & \multirow{2}{*}{$\begin{array}{c}\text { Mean } \\
\text { Pollen } \\
\text { Viability }\end{array}$} \\
\hline & & & & & & Cluster 1 & Cluster 2 & & & & \\
\hline$F$. v. subsp. bracteata & OR-MRD & $10,9,15,37$ & $\mathrm{C} / \mathrm{B}$ & 0.20 & 2 & 0.004 & 0.996 & 2.58 & 0.15 & 0.3 & 0.75 \\
\hline F. v. subsp. bracteata & WA-DC & $7,7,7,20$ & B & 0 & 2 & 0.004 & 0.996 & 2.00 & 0.13 & 0.1 & 0.81 \\
\hline F. v. subsp. bracteata & OR-FB & $9,10,15,9$ & $\mathrm{C}$ & 0 & $2 / 1$ & 0.009 & 0.991 & 2.13 & $0.46^{*}$ & 0.3 & 0.77 \\
\hline F. v. subsp. bracteata & CA-PDL & $9,10,15,20$ & $\mathrm{~B}$ & 0 & 2 & 0.011 & 0.989 & 1.94 & 0.08 & $0.05^{\prime \prime}$ & 0.67 \\
\hline F. v. subsp. bracteata & CA-WMR & $9,10,15,22$ & B & 0 & 2 & 0.011 & 0.989 & 2.07 & 0.09 & 0 & 0.87 \\
\hline F. v. subsp. bracteata & OR-ES & $9,10,11,38$ & $\mathrm{G} / \mathrm{C} / \mathrm{E}$ & 0.64 & $1 / 2$ & 0.009 & 0.991 & 2.20 & $0.29 *$ & 0.18 & 0.79 \\
\hline F. v. subsp. bracteata & ID-SFR & $7,9,8,9$ & $\mathrm{E} / \mathrm{C}$ & 0.46 & $1 / 2$ & 0.004 & 0.996 & 1.60 & 0.27 & $0.1 "$ & 0.71 \\
\hline F. v. subsp. bracteata & CO-SCR & $10,12,9,11$ & $\mathrm{C} / \mathrm{G}$ & 0.41 & 1 & 0.034 & 0.966 & 1.46 & $0.66^{*}$ & $0.18^{\prime \prime}$ & 0.73 \\
\hline F. v. subsp. bracteata & NM-LNF & $9,10,18,36$ & $\mathrm{~F}$ & 0 & 1 & 0.972 & 0.028 & 2.36 & $0.60^{*}$ & 0.46 & 0.80 \\
\hline F. v. subsp. californica & CA-INASD & $2,3,4,4$ & $\mathrm{C}$ & 0 & 2 & 0.005 & 0.995 & 1.80 & $0.74 *$ & 0 & 0.90 \\
\hline F. v. subsp. californica & CA-SBNF & $8,10,10,18$ & $\mathrm{C}$ & 0 & 2 & 0.005 & 0.995 & 1.20 & N/A & 0 & 0.85 \\
\hline F. mexicana & MX-LV & $9,10,15,27$ & $\mathrm{C}$ & 0 & 1 & 0.004 & 0.996 & 1.58 & $0.62 *$ & 0 & 0.84 \\
\hline F. v. subsp. americana & IA-SSP & $0,4,6,6$ & na & na & 1 & 0.979 & 0.021 & 1.53 & 0.07 & 0 & 0.95 \\
\hline F. v. subsp. americana & ONT-GRL & $10,10,10,10$ & $\mathrm{D} / \mathrm{H}$ & 0.46 & 1 & 0.789 & 0.211 & 2.12 & 0.76 & 0 & 0.94 \\
\hline F. v. subsp. americana & NH-FP & $3,3,18,18$ & $\mathrm{H}$ & 0 & 1 & 0.996 & 0.004 & 1.39 & 0.26 & $0^{\prime \prime}$ & 0.96 \\
\hline
\end{tabular}




\footnotetext{
Note. Population code is given, see Table A1 for location details. $\mathrm{N}$ is the number of individuals used for the mitochondrial, chloroplast, and nuclear sequencing analyses, and for estimating proportion of females, respectively. Mitotype reflects the combination of sequence data for atp 8 -orf 225 and atp 8 (Fig. $2 b$, Table A2). Chlorotype is sequence data from rpoC2 (Fig. 2a, Table A2). Order in polymorphic populations reflects majority/minority types. Nuclear membership in two clusters based on STRUCTURE analyses (Fig. 3). Allelic richness (number of alleles per locus) and inbreeding coefficients $\left(F_{\text {IS }}\right)$. The proportion of females and pollen viability of hermaphrodites from each population.

"Determined from field-collected plants grown in the greenhouse. All other proportions estimated from plants observed in the field.

*Inbreeding coefficient is significant.

Na: not available.
} 


\section{Figure captions}

Fig. 1. Schematic of the distributions of Fragaria vesca subspecies and F. mexicana in North America based on data from Staudt (1999) and Liston et al. (2014).

Fig.2. Minimum spanning networks of $F$. vesca haplotypes. (A) 351 bp of $r p o C 2$ cpDNA, (B) 776 bp of concatenated atp8-orf 225 and atp 8 mtDNA, (C) 351 bp of atp 8 mtDNA, (D) 425 bp of atp8-orf225 mtDNA. Colors indicate taxa and shades within them populations. Population codes reflect state and population moniker as in Table A1. Letters correspond to mitotype (Table A3) and numbers to chlorotype. Black dots represent unknown ancestral haplotypes.

Fig.3. Geographic patterns of diversity in the cytoplasmic genes in North American diploid $F$. vesca. Large symbols represent deeply sampled populations, while small ones represent single individuals (see Table A1). The outer circle represents mitotype, with pattern representing the concatenated of atp 8 and atp8-orf225 genes (Fig. 2B). Dashed lines indicate that mitotype is unknown. The inner circle shows chlorotype based on rpoC2 (see Table A2). Squares represent chlorotypes reported in Njuguna et al. (2013).

Fig.4. STRUCTURE analysis of nuclear microsatellite loci showing population and individual membership to $K=2$ genetic groups. Yellow represents cluster 1 ( $F$. v. subsp. americana type). Blue represents cluster 2 (F. v. subsp. bracteata type). Each population is identified by the population code name (Table 1$)$ followed by the taxon in parentheses $(\mathrm{A}=F$. v. subsp. americana; $\mathrm{B}=F$. v. subsp. bracteata $\mathrm{C}=F$. v. subsp. californica $; \mathrm{M}=F$. mexicana). Cytoplasmic membership for each population is illustrated above. The outer circle represents mitotype, with pattern representing the concatenated of atp 8 and atp 8 -orf 225 genes (Fig. 2B). The inner circle shows chlorotype based on rpoC2 (see Table A2). Dashed lines indicate that mitotype is unknown. 


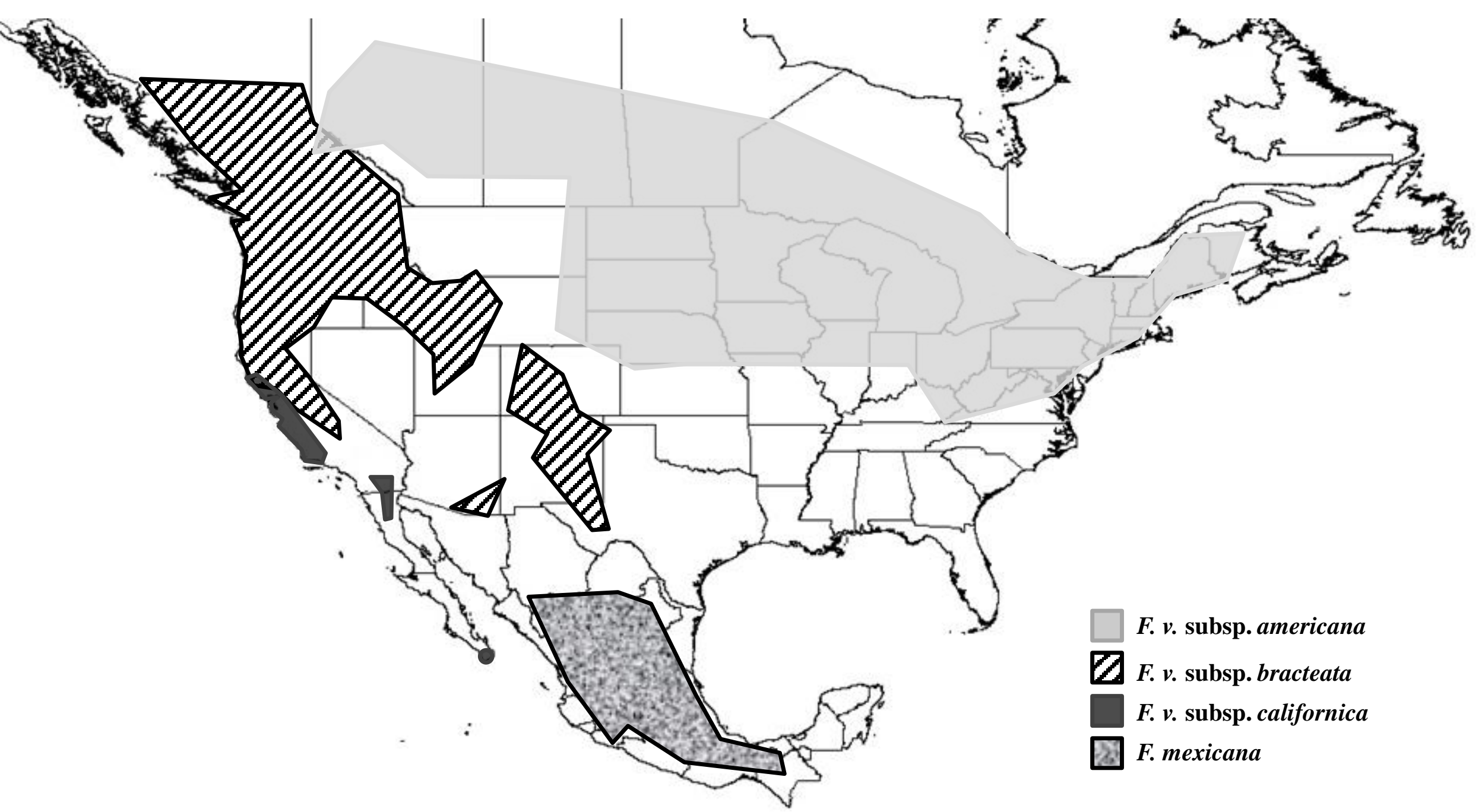




\section{Page 35 of 42}




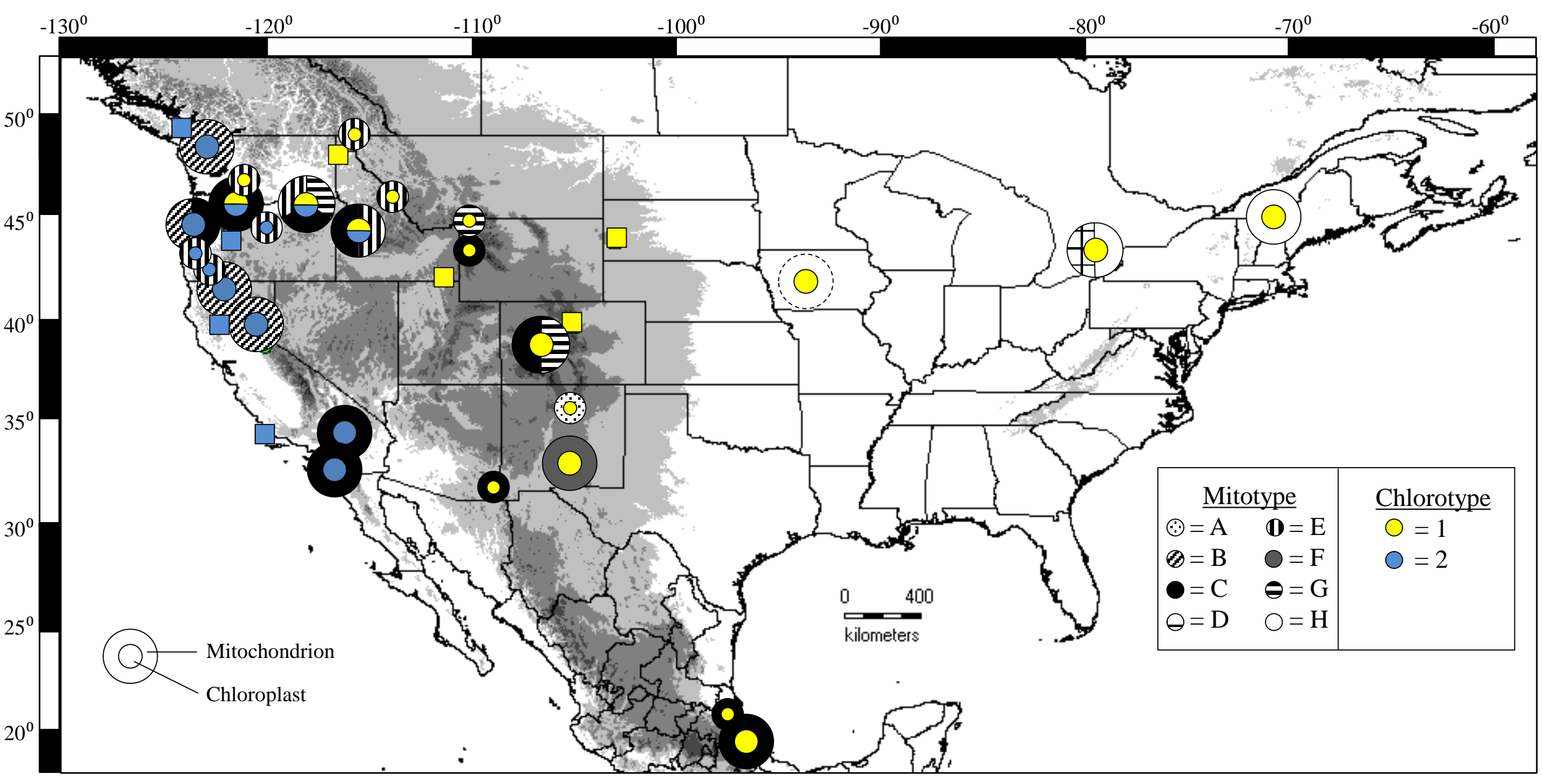




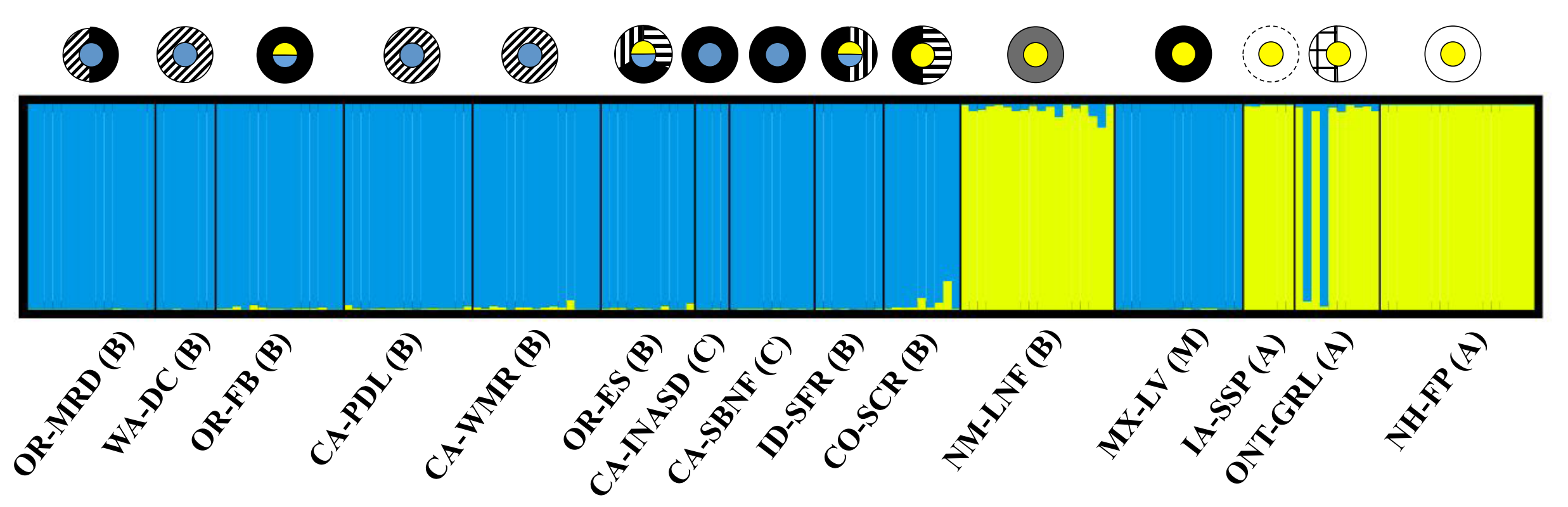


Table A1

Collection information for sampled populations/individuals of diploid North American strawberry

\begin{tabular}{|c|c|c|c|c|c|c|c|c|}
\hline Taxon & Population/Accession Name & Population Code & State/Province, Country & Latitude $(\mathrm{N})$ & Longitude (W) & $\mathrm{N}$ & Collection Type & DNA \\
\hline F. v. subsp. bracteata & NCGR PI 616651* & . & British Columbia, Canada & 49.150 & -124.500 & 1 & Leaf tissue & $\mathrm{C}$ \\
\hline F. v. subsp. bracteata & Mary's Road & OR-MRD & Oregon, USA & 44.496 & -123.540 & 16 & Whole plant & $\mathrm{C}, \mathrm{M}, \mathrm{N}$ \\
\hline F. v. subsp. bracteata & Dungeness Campground & WA-DC & Washington, USA & 48.139 & -123.190 & 7 & Whole plant & $\mathrm{C}, \mathrm{M}, \mathrm{N}$ \\
\hline F. v. subsp. bracteata & NCGR PI 664439 & FVB1 & Oregon, USA & 42.111 & -122.709 & 1 & Leaf tissue & $\mathrm{C}, \mathrm{M}$ \\
\hline F. v. subsp. bracteata & Fishermen's Bend & OR-FB & Oregon, USA & 44.756 & -122.520 & 15 & Whole plant & $\mathrm{C}, \mathrm{M}, \mathrm{N}$ \\
\hline F. v. subsp. bracteata & NCGR PI 664438 & FVB2 & California, USA & 41.352 & -122.285 & 1 & Leaf tissue & $\mathrm{C}, \mathrm{M}$ \\
\hline F. v. subsp. bracteata & NCGR PI 551835* & . & Oregon, USA & 44.500 & -122.000 & 1 & Leaf tissue & $\mathrm{C}$ \\
\hline F. v. subsp. bracteata & NCGR PI 664413 & FVB3 & Oregon, USA & 45.373 & -121.823 & 1 & Leaf tissue & $\mathrm{C}, \mathrm{M}$ \\
\hline F. v. subsp. bracteata & Paradise Lake & CA-PDL & California, USA & 39.859 & -121.581 & 15 & Whole plant & $\mathrm{C}, \mathrm{M}, \mathrm{N}$ \\
\hline F. v. subsp. bracteata & NCGR PI 551807* & . & California, USA & 39.782 & -121.321 & 1 & Leaf tissue & $\mathrm{C}$ \\
\hline F. v. subsp. bracteata & NCGR PI 551749* & . & California, USA & 34.504 & -120.498 & 1 & Leaf tissue & $\mathrm{C}$ \\
\hline F. v. subsp. bracteata & White Meadow Road & CA-WMR & California, USA & 38.774 & -120.456 & 17 & Whole plant & $\mathrm{C}, \mathrm{M}, \mathrm{N}$ \\
\hline F. v. subsp. bracteata & NCGR PI 551551 & FVB4 & Oregon, USA & 44.517 & -120.371 & 1 & Leaf tissue & $\mathrm{C}, \mathrm{M}$ \\
\hline F. v. subsp. bracteata & Emigrant Springs & OR-ES & Oregon, USA & 45.543 & -118.460 & 11 & Whole plant & $\mathrm{C}, \mathrm{M}, \mathrm{N}$ \\
\hline F. v. subsp. bracteata & NCGR PI 551646* & . & Idaho, USA & 48.538 & -116.357 & 1 & Leaf tissue & $\mathrm{C}$ \\
\hline F. v. subsp. bracteata & NCGR PI 551644 & FVB5 & Idaho, USA & 48.978 & -116.157 & 1 & Leaf tissue & $\mathrm{C}, \mathrm{M}$ \\
\hline F. v. subsp. bracteata & South Fork Rd & ID-SFR & Idaho, USA & 44.014 & -115.512 & 9 & Seed & $\mathrm{C}, \mathrm{M}, \mathrm{N}$ \\
\hline F. v. subsp. bracteata & NCGR PI 551525 & FVB6 & Montana, USA & 46.031 & -114.171 & 1 & Leaf tissue & $\mathrm{C}, \mathrm{M}$ \\
\hline F. v. subsp. bracteata & NCGR PI 651550* & . & Idaho, USA & 42.163 & -111.646 & 1 & Leaf tissue & $\mathrm{C}$ \\
\hline
\end{tabular}




\begin{tabular}{|c|c|c|c|c|c|c|c|c|}
\hline F. v. subsp. bracteata & NCGR PI 551523 & FVB7 & Wyoming, USA & 43.634 & -110.547 & 1 & Leaf tissue & $\mathrm{C}, \mathrm{M}$ \\
\hline F. v. subsp. bracteata & NCGR PI 551874 & FVB8 & Wyoming, USA & 44.667 & -110.500 & 1 & Leaf tissue & $\mathrm{C}, \mathrm{M}$ \\
\hline F. v. subsp. bracteata & NCGR PI 637952 & FVB9 & Arizona, USA & 31.882 & -109.284 & 1 & Leaf tissue & $\mathrm{C}, \mathrm{M}$ \\
\hline F. v. subsp. bracteata & Spring Creek Road & CO-SCR & Colorado, USA & 38.762 & -106.767 & 10 & Seed & $\mathrm{C}, \mathrm{M}, \mathrm{N}$ \\
\hline F. v. subsp. bracteata & Lincoln National Forest & NM-LNF & New Mexico, USA & 32.968 & -105.750 & 15 & Whole plant & $\mathrm{C}, \mathrm{M}, \mathrm{N}$ \\
\hline F. v. subsp. bracteata & NCGR PI 637947 & FVB10 & New Mexico, USA & 35.703 & -105.686 & 1 & Leaf tissue & $\mathrm{C}, \mathrm{M}$ \\
\hline F. v. subsp. bracteata & NCGR PI 657860* & . & Colorado, USA & 39.693 & -105.501 & 1 & Leaf tissue & $\mathrm{C}$ \\
\hline F. v. subsp. bracteata & NCGR PI 551881* & . & South Dakota, USA & 43.833 & -103.500 & 1 & Leaf tissue & $\mathrm{C}$ \\
\hline F. v. subsp. californica & Inaja Picnic Area & CA-INASD & California, USA & 33.023 & -117.095 & 5 & Whole plant & $\mathrm{C}, \mathrm{M}, \mathrm{N}$ \\
\hline F. v. subsp. californica & San Bernadino National Forest & CA-SBNF & California, USA & 34.163 & -116.911 & 10 & Whole plant & $\mathrm{C}, \mathrm{M}, \mathrm{N}$ \\
\hline F. mexicana & Las Vigas & MX-LV & Veracruz, Mexico & 19.539 & -97.174 & 15 & Seed & $\mathrm{C}, \mathrm{M}, \mathrm{N}$ \\
\hline F. mexicana & Perote & MX-PE & Veracruz, Mexico & 19.381 & -97.090 & 1 & Seed & $\mathrm{C}, \mathrm{M}$ \\
\hline F. v. subsp. americana & Springbrook State Park & IA-SSP & Iowa, USA & 41.775 & -94.465 & 6 & Seed & $\mathrm{C}, \mathrm{M}, \mathrm{N}$ \\
\hline F. v. subsp. americana & Guelph Radial Line & ONT-GRL & Ontario, Canada & 43.549 & -80.218 & 10 & Leaf tissue & $\mathrm{C}, \mathrm{M}, \mathrm{N}$ \\
\hline F. v. subsp. americana & Fish Pond Road & NH-FP & New Hampshire, USA & 44.871 & -71.504 & 15 & Seed & $\mathrm{C}, \mathrm{M}, \mathrm{N}$ \\
\hline
\end{tabular}

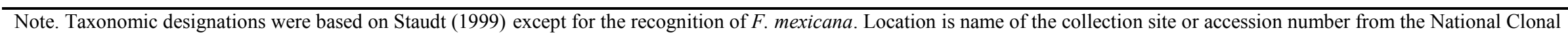

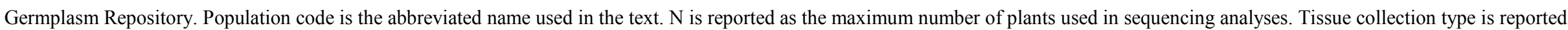

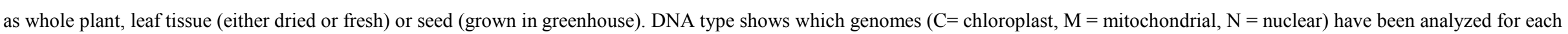
population/individual in the study. Asterisks indicate individuals with known sequences from Njuguna et al. 2013. 
Primer sequences for the mitochondrial genes and nuclear microsatellites screened to assess polymorphism

\begin{tabular}{|c|c|c|c|c|c|}
\hline Genome & $\begin{array}{l}\text { Gene/SSR } \\
\text { Locus }\end{array}$ & Primer sequence & $\begin{array}{l}\text { Expected } \\
\text { product } \\
\text { size }\end{array}$ & $\begin{array}{l}\text { Annealing } \\
\text { temperature } \\
\left({ }^{\circ} \mathrm{C}\right)\end{array}$ & Source \\
\hline \multirow[t]{2}{*}{ Chloroplast } & rpoC2 & F: GGAATTCGAAATTCTCCCGTTT & & & \\
\hline & & R: AGGGATAATCTAGAGCTTCGAGTTG & 700 & 52 & Njuguna et al. 2013 \\
\hline \multirow[t]{2}{*}{ Mitochondrial } & atp 4 & F: CACGACTAGAAAGATGCTATTTGC & & & \\
\hline & & R: TAAGACCACCAAGCCCTCTC & 526 & 54 & Barr et al. 2007 \\
\hline \multirow[t]{2}{*}{ Mitochondrial } & atp6 & F: CAATTTGCCATTCTCCCATT & & & \\
\hline & & R: TGATGGAGATTTGTAGCATCATTC & 746 & 52 & Barr et al. 2007 \\
\hline \multirow[t]{2}{*}{ Mitochondrial } & atp 8 & F: CTTCTGGTCATGCCTTTTCC & & & \\
\hline & & R: CTTGGCCGTGTGGAACAT & 425 & 54 & In this study \\
\hline \multirow[t]{2}{*}{ Mitochondrial } & $\operatorname{atp} 9$ & F: ATAGGTGCCGGAGCTGCTA & & & \\
\hline & & R: CGGAATACGGATGAGATCAAA & 203 & 54 & Darracq et al. 2012 \\
\hline \multirow[t]{2}{*}{ Mitochondrial } & $c o b$ & F: TGTTTGGTGTCTCGGAGTTG & & & \\
\hline & & R: TAACAAATGGTGCCTCCACA & 713 & 54 & Touzet and Delph 2009 \\
\hline \multirow[t]{2}{*}{ Mitochondrial } & $\cos 3$ & F: CCAAGTCCATGGCCTATTTC & & & \\
\hline & & R: CAAATGGGAATAACCGAACC & 730 & 52 & Barr et al. 2007 \\
\hline \multirow[t]{2}{*}{ Mitochondrial } & nad6 & F: TGCTTTGGTCTCTGGTTTGA & & & \\
\hline & & R: GTAGATCGTGACGGGGTCTG & 589 & 54 & Case and Willis 2008 \\
\hline \multirow[t]{2}{*}{ Mitochondrial } & $\operatorname{nad} 9$ & F: TGGGAGACTTTACCTAAGAAATGG & & & \\
\hline & & R: TCCGTCGCTACGCTGTTC & 540 & 54 & Case and Willis 2008 \\
\hline \multirow[t]{2}{*}{ Mitochondrial } & rpsl 1 & F: TTTGAGTCGATCATTTCCAAGA & & & \\
\hline & & R: AGTAATGAAACCCCCGATGC & 496 & 52 & In this study \\
\hline \multirow[t]{2}{*}{ Mitochondrial } & $\begin{array}{l}\text { atp8- } \\
\text { orf } 225\end{array}$ & F: CATTTAATAATGCAGGGGTACG & & & \\
\hline & & R: CTGTGGTAGTCTTTCGTGG & 425 & 48 & In this study \\
\hline
\end{tabular}




\begin{tabular}{|c|c|c|c|c|c|}
\hline \multirow[t]{2}{*}{ Nuclear } & \multirow[t]{2}{*}{ CX661264 } & \multicolumn{4}{|l|}{ F: GTTCTCAGATCCCTCTACCG } \\
\hline & & R: AATTTGCAGCCATCAAGTCC & $483-487$ & 59 & Spigler et al. 2008 \\
\hline \multirow[t]{2}{*}{ Nuclear } & ARSFL007 & F: GCGCGCATAAGGCAACAAAG & & & \\
\hline & & R: GCGAATGGCAATGACATCTTCTCT & $227-238$ & 59 & Lewers et al. 2005 \\
\hline \multirow[t]{2}{*}{ Nuclear } & CX661603 & F: ATCAACCACACCGCTACTCC & & & \\
\hline & & R: ATTTACGAAAATGCCATCGG & $99-128$ & 59 & Spigler et al. 2008 \\
\hline \multirow[t]{2}{*}{ Nuclear } & UDF002 & F: TATGGCCAGGATTGTTTGCT & & & \\
\hline & & R: TAGGAGGAGGCGTTGAAATG & $132-148$ & 59 & Sargent et al. 2004 \\
\hline \multirow[t]{2}{*}{ Nuclear } & Fvi11 & F: GCATCATCGTCATAATGAGTGC & & & \\
\hline & & R: GGCTTCATCTCTGCAATTCAA & $320-358$ & 59 & Ashley et al. 2003 \\
\hline
\end{tabular}




\section{Table A3}

DNA polymorphism for atp8-orf225 and atp8 for four diploid Fragaria taxa.

\begin{tabular}{|c|c|c|c|c|c|c|c|c|}
\hline Gene & \multicolumn{3}{|c|}{ atp8-orf 225} & \multicolumn{5}{|c|}{ atp 8} \\
\hline \multicolumn{9}{|l|}{ Variable } \\
\hline Locus & 20 & 130 & 164 & 153 & 202 & 364 & 369 & 439 \\
\hline \multicolumn{9}{|l|}{ Mitotype } \\
\hline A & $\underline{\mathrm{G}}$ & $\underline{\mathrm{C}}$ & $\underline{\mathrm{G}}$ & $\mathrm{G}$ & A & $\underline{\mathrm{G}}$ & $\underline{\mathrm{G}}$ & $\mathrm{C}$ \\
\hline B & $\underline{T}$ & $\underline{\mathrm{A}}$ & $\underline{\mathrm{G}}$ & G & A & $\underline{\mathrm{G}}$ & $\underline{\mathrm{G}}$ & $\mathrm{C}$ \\
\hline $\mathrm{C}$ & $\underline{T}$ & $\underline{\mathrm{C}}$ & $\underline{\mathrm{G}}$ & G & A & $\underline{\mathrm{G}}$ & $\underline{\mathrm{G}}$ & $\mathrm{C}$ \\
\hline $\mathrm{D}$ & $\underline{T}$ & $\underline{\mathrm{C}}$ & $\underline{\mathrm{T}}$ & G & A & $\underline{\mathrm{G}}$ & $\underline{\mathrm{G}}$ & $\mathrm{C}$ \\
\hline $\mathrm{E}$ & $\underline{T}$ & $\underline{\mathrm{C}}$ & $\underline{\mathrm{G}}$ & G & A & $\underline{\mathrm{G}}$ & $\underline{\mathrm{T}}$ & $\mathrm{C}$ \\
\hline $\mathrm{F}$ & $\underline{\mathrm{G}}$ & $\underline{\mathrm{C}}$ & $\underline{\mathrm{G}}$ & G & A & $\underline{\mathrm{G}}$ & $\underline{T}$ & $\mathrm{C}$ \\
\hline G & $\underline{T}$ & $\underline{\mathrm{C}}$ & $\underline{\mathrm{G}}$ & $\mathrm{G}$ & A & $\underline{\mathrm{T}}$ & $\underline{\mathrm{T}}$ & $\mathrm{C}$ \\
\hline $\mathrm{H}$ & $\underline{\mathrm{T}}$ & $\underline{\mathrm{C}}$ & $\underline{\mathrm{G}}$ & $\mathrm{T}$ & $\mathrm{C}$ & $\underline{\mathrm{T}}$ & $\underline{\mathrm{T}}$ & $\mathrm{T}$ \\
\hline
\end{tabular}

Note. For each of the mitotypes (Table 1 and depicted in Fig.2) the variable sites in atp8-orf225 and atp 8 (numbered from the first codon position) are given. Underline indicates position at which nonsynonymous substitutions occur. Mitotype A occurred in a single herbarium sample. 